\title{
Study Subject Withdrawal by Parent or Guardian
}

National Cancer Institute

\section{Source}

National Cancer Institute. Study Subject Withdrawal by Parent or Guardian. NCI

Thesaurus. Code C102355.

An indication that a study participant has been removed from the study by the parent or legal guardian. 